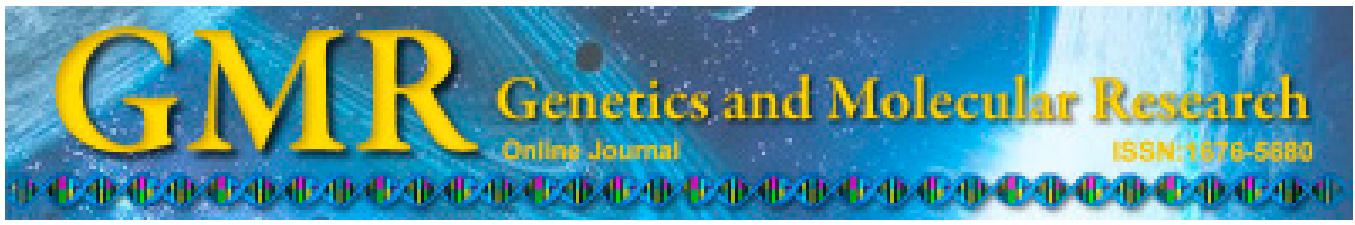

\title{
Genetic polymorphisms in the carbonic anhydrase VI gene and dental caries susceptibility
}

\author{
Z.-Q. Li $^{1,3}$, X.-P. Hu ${ }^{1}$, J.-Y. Zhou ${ }^{1}$, X.-D. Xie ${ }^{2}$ and J.-M. Zhang ${ }^{1}$
}

${ }^{1}$ School of Stomatology, Northwest University for Nationalities, Lanzhou, Gansu, China

${ }^{2}$ Institute of Genetic Research, Lanzhou University, Lanzhou, Gansu, China

${ }^{3}$ Key Laboratory of Stomatology of State Ethnic Affairs Commission, Northwest University for Nationalities, Lanzhou, Gansu, China

Corresponding author: X.-P. Hu

E-mail: 491357863@qq.com

Genet. Mol. Res. 14 (2): 5986-5993 (2015)

Received August 26, 2014

Accepted January 2, 2015

Published June 1, 2015

DOI http://dx.doi.org/10.4238/2015.June.1.16

ABSTRACT. We investigated the role of 7 single nucleotide polymorphisms in the carbonic anhydrase (CA) VI gene (rs2274328, rs17032907, rs11576766, rs2274333, rs10864376, rs3765964, and rs6680186) and the possible association between these polymorphisms and dental caries susceptibility in a Northwestern Chinese population. We collected samples from 164 high caries experience and 191 very low caries experience and conducted a case-control study according to the number of decayed, missing, and filled teeth index and genotyped the 7 polymorphisms using a 384-well plate format with the Sequenom MassARRAY platform. Individuals carrying the rs17032907 TT genotype were more likely to have an increased risk of dental caries compared with carriers of the $\mathrm{C} / \mathrm{C}$ genotype in the co-dominant model, with an odds ratio (95\% confidence interval) of 2.144 (1.096-4.195). We also found that the haplotype (ACA) (rs2274328, rs17032907 and rs 11576766) was associated with a low number of decayed, missing, and filled teeth index with an odds ratio (95\% confidence interval) of 
0.635 (0.440-0.918). However, we found no association between dental caries susceptibility and the rs2274328, rs11576766, rs2274333, rs10864376, rs3765964, and rs6680186 polymorphisms and other haplotypes. The rs17032907 genetic variant and the haplotype (ACA) of CA VI may be associated with dental caries susceptibility.

Key words: Dental caries; Number of decayed, missing, and filled teeth; Sequenom MassArray; Single-nucleotide polymorphisms

\section{INTRODUCTION}

Dental caries is a chronic infectious disease that is common worldwide. This disease can cause dental pain, tooth loss, and more severe systemic disease (Mattila et al., 1995; Petersen, 2003). Studies of twins (Shuler, 2001), families and animal breeding (Hunt, 1944; Klein, 1946), and genomics (Shelling and Ferguson, 2007) indicated that dental caries has an important genetic component and that $40-65 \%$ of caries risk may be related to genetic factors (Bretz et al., 2005). It has been widely established that dental caries is mostly influenced by environmental factors such as microbial, diet, oral hygiene, and host aspects (LenanderLumikari et al., 2000; Petersen, 2003; Nariyama et al., 2004); however, there is increasing evidence for a genetic component in caries susceptibility (Patir et al., 2008; Azevedo et al., 2010; Ozturk et al., 2010; Kang et al., 2011). Therefore, genes may have an important role in the initiation and progression of dental caries.

Carbonic anhydrases (CAs) participate in the maintenance of $\mathrm{pH}$ homeostasis and $\mathrm{CO}_{2}$ and ion transport in human tissue by catalyzing the reversible hydration of carbon dioxide in the following reaction: $\mathrm{CO}_{2}+\mathrm{H}_{2} \mathrm{O} \leftrightarrow \mathrm{HCO}_{3}^{-}+\mathrm{H}^{+}$(Davenport, 1939; Kivelä, 1997). At least 11 isozymes of CA and CA-related proteins have been identified in mammals, and more than 2 are expressed in salivary physiology (Kadoya et al., 1987). Among these, carbonic anhydrase isoenzyme VI (CA VI) is the only secretory isoenzyme in the mammalian CA gene family. It is exclusively expressed in the serous acinar cells of the parotid and submandibular glands, from where it is secreted into the saliva and plays a key role in the oral microenvironment, such as maintaining oral pH (Kivelä et al., 1999a).

Salivary CA VI has been implicated in taste (Henkin et al., 1999) and gastrointestinal dysfunctions (Kivelä et al., 1999a). In 1974, Szabó (1974) reported higher CA activity levels in caries-free children than in children with active caries. Further, Kivela et al. (1999b) showed that salivary CA VI is negatively correlated with number of decayed, missing, and filled teeth (DMFT) index values, particularly in individuals with poor oral hygiene, but no correlation was found between salivary CA VI concentration and Lactobacillus or Streptococcus mutans counts. Moreover, CA VI binds to the enamel pellicle and retains its enzymatic activity on the tooth surface, which may catalyze the conversion of salivary bicarbonate and microbe-delivered hydrogen ions to carbon dioxide and water (Leinonen et al., 1999; Kimoto et al., 2006). It was recently reported that a C/T polymorphism in CA VI may be associated with salivary buffer capacity (Peres et al., 2010). These data suggested that salivary CA VI plays an important role in protecting the teeth from caries.

The CA VI gene is located at 1p36.2, and contains 8 exons and 7 introns (Jiang and Gupta, 1999). Previous studies (Peres et al., 2010; Padiglia et al., 2010; Koç et al., 2012) examining CA VI gene polymorphisms mainly focused on exon 2 or 3 , as these polymorphisms 
result in changes in the amino acid sequence in the secreted protein and may interfere with enzyme function. However, the introns may be involved in the regulation of gene expression, but no studies have examined the relationship between polymorphisms in the intron regions of the CA VI gene and caries susceptibility. Moreover, studies examining the association between genetic polymorphisms in CA VI genes and dental caries are rare (Padiglia et al., 2010; Koç et al., 2012). To identify potential markers for predicting the susceptibility to dental caries, we investigated the association between 7 single nucleotide polymorphisms (SNPs) in the CA VI gene and dental caries in subjects from northwestern China.

\section{MATERIAL AND METHODS}

\section{Study subjects}

We recruited 355 individuals for participation in the study. All participants were permanent residents from an autonomous county in the Gansu Province in northwestern China, who were obtained and recruited during their health examinations with the help of China's ethnic affairs commission in 2011. All individuals received an oral and dental examination performed by 2 associate professors who had undergone uniform training to ensure standardization of inspections. The kappa value was determined to be 0.8. DMFT was assessed based on World Health Organization criteria (WHO, 1997). The subjects were divided into 2 groups according to DMFT index (Deeley et al., 2008; Kang et al., 2011). The high caries experience group (DMFT $\geq 3$, the case group) included 164 subjects, while the low caries experience (DMFT $\leq 2$, control group) included 191 subjects.

All subjects from the Northwest Chinese population had a similar socioeconomic status and showed no significant differences in gender or age among groups. The study was performed in accordance with the guidelines set by the ethics committee of Northwest University for Nationalities, and informed consent was obtained from all subjects.

\section{DNA collection and genotyping}

Genomic DNA was prepared from blood samples using a DNA Micro Kit (Shanghai Lifefeng Biotechnology Co. Ltd., Shanghai, China) according to manufacturer instructions. All genotypes in the7 SNPs within the CA VI gene were determined on a 384-well plate format using the Sequenom MassARRAY RS1000 platform following the manufacturer protocol (Sequenom, San Diego, CA, USA). Polymerase chain reaction (PCR) products were verified by $1.0 \%$ agarose gel electrophoresis and visualized by ethidium bromide staining under ultraviolet light. Genotyping was performed without knowledge of the dental caries status of the subjects, and reproducibility was confirmed by repeat analysis of a randomly chosen subgroup of $5 \%$ of the study participants. The PCR primers were designed using the AssayDesigner 3.1 software and synthesized by Biotechnology Company (Shanghai, China); primer sequences are shown in Table 1.

\section{Statistical analysis}

Demographic characteristics of the 2 groups were described as the frequencies and percentages, whereas descriptive statistics were presented as the mean and standard deviations 
for continuous measures. Hardy-Weinberg equilibrium for the 7 SNPs was assessed using a chi-square $\left(\chi^{2}\right)$ test. The differences in genotype frequencies between groups were tested using a chi-square test, and dominant and co-dominant genetic models were used to evaluate the associations between each SNP and caries risk. For each polymorphism, the odds ratio (OR) and 95\% confidence interval (CI) were calculated by unconditional logistic regression analysis adjusted for potential risk factors. A linkage disequilibrium block of polymorphisms was tested using Haploview 4.2 and estimated with D' (Lewontin, 1964). A P value of less than 0.05 was considered to be statistically significant. All statistical analyses were performed using the SPSS software, version 13.0 for Windows (SPSS Inc., Chicago, IL, USA).

\begin{tabular}{|c|c|}
\hline $\mathrm{dbSNP}$ & Primer sequence \\
\hline \multirow[t]{2}{*}{ rs2274328 } & F: 5'-ACGTTGGATGTACCTGTGTGGCCATTGTTG-3' \\
\hline & R: 5'-ACGTTGGATGCGGTACAACCCCTCCTTGAA-3' \\
\hline \multirow[t]{2}{*}{ rs17032907 } & F: 5'-ACGTTGGATGCTAAAAAATGCCCCCTCCTG-3' \\
\hline & R: 5'-ACGTTGGATGACTTGTGCAGAATATCCTCC-3' \\
\hline \multirow[t]{2}{*}{ rs11576766 } & F: 5'-ACGTTGGATGGGTCACAGGACTTAGTGTTC-3' \\
\hline & R: 5'-ACGTTGGATGGGATTACAGGCATGAACCAC-3' \\
\hline \multirow[t]{2}{*}{ rs2274333 } & F: 5'-ACGTTGGATGATGTATACAGTGCCGTCAGC-3' \\
\hline & R: 5'-ACGTTGGATGTGTTCACCTACTCTGCTCTC-3' \\
\hline \multirow[t]{2}{*}{ rs10864376 } & F: 5'-ACGTTGGATGGTATCTGCACACAAGCTCTC-3' \\
\hline & R: 5'-ACGTTGGATGTCTGCTTCTTCTTTCTCTCC-3' \\
\hline \multirow[t]{2}{*}{ rs3765964 } & F: 5'-ACGTTGGATGCTTGGATTTTGGCTTCTCCC-3' \\
\hline & R: 5'-ACGTTGGATGGAAAACGCCTATATCCCCTC-3' \\
\hline \multirow[t]{2}{*}{ rs6680186 } & F: 5'-ACGTTGGATGCCAGGTCAGAAATGGATCAG-3' \\
\hline & R: 5'-ACGTTGGATGAGTGCAGTGGCTATTCACAG-3' \\
\hline
\end{tabular}

\section{RESULTS}

The demographic and clinical characteristics of the study population are summarized in Table 2. The high caries experience group (DMFT $\geq 3$ ) included 164 subjects ( 84 male and 80 female, mean age $51.16 \pm 9.48$ years) and the low caries experience group (DMFT $\leq 2)$ included 191 subjects ( 99 male and 92 female, mean age $47.44 \pm 9.67$ years). DMFT index values ranged from $0-22$. There were no statistical differences in concomitant systemic disease between the populations, or in gender and age $(\mathrm{P}>0.05)$.

Seven different polymorphisms were examined in the CA-VI gene. Genotype distributions of the 7 SNPs are shown in Table 3. In the low caries experience group, the minor allele frequencies were in Hardy-Weinberg equilibrium (Table 3).

Multivariate logistic regression analysis was conducted to evaluate the effect of the 7 SNPs on caries risk (Table 4). Individuals with the rs17032907 TT genotype were more likely to have a higher caries experience than carriers of the $\mathrm{C} / \mathrm{C}$ genotype in the co-dominant model, with an OR (95\%CI) of 2.144 (1.096-4.195). However, we found no association between increased or decreased risk of caries and the rs2274328, rs11576766, rs2274333, rs10864376, rs3765964, or rs6680186 polymorphisms in CA-VI.

We demonstrated that a linkage disequilibrium block between 3 SNPs (rs2274328, rs17032907and rs11576766] within the CA VI gene ( $\mathrm{D}^{\prime}>0.9$, the block in Figure 1), and the haplotype (ACA) may be associated with low DMFT index; however, other haplotype polymorphisms in CA VI showed no association with dental caries susceptibility (Table 5). 
Table 2. Demographic characteristics of the subjects.

\begin{tabular}{|c|c|c|c|c|c|c|}
\hline Characteristics & $\begin{array}{l}\text { Higher caries experience } \\
(\mathrm{DMFT} \geq 3) \mathrm{N}=164\end{array}$ & $\%$ & $\begin{array}{l}\text { Very low caries experience } \\
(\mathrm{DMFT} \leq 2) \mathrm{N}=191\end{array}$ & $\%$ & $\chi^{2}$ & $P$ \\
\hline Age (means $\pm S D$ ) (years) & $51.16 \pm 9.48$ & & $47.44 \pm 9.67$ & & 0.47 & 0.238 \\
\hline Gender & & & & & 0.13 & 0.908 \\
\hline Male & 84 & 51.2 & 99 & 51.8 & & \\
\hline Female & 80 & 48.8 & 92 & 48.2 & & \\
\hline DMFT scores & & & & & & \\
\hline 0 & & & 40 & & & \\
\hline 1 & & & 64 & & & \\
\hline 2 & & & 87 & & & \\
\hline 3 & 26 & & & & & \\
\hline 4 & 15 & & & & & \\
\hline 5 & 12 & & & & & \\
\hline 6 & 19 & & & & & \\
\hline 7 & 11 & & & & & \\
\hline 8 & 3 & & & & & \\
\hline 9 & 15 & & & & & \\
\hline 10 & 8 & & & & & \\
\hline 11 & 5 & & & & & \\
\hline 12 & 9 & & & & & \\
\hline 14 & 11 & & & & & \\
\hline 15 & 13 & & & & & \\
\hline 16 & 10 & & & & & \\
\hline 19 & 4 & & & & & \\
\hline 20 & 2 & & & & & \\
\hline 22 & 1 & & & & & \\
\hline
\end{tabular}

Table 3. Association between the 7 CA VI polymorphisms and caries risk.

\begin{tabular}{lcccc}
\hline dbSNP & Major/minor allele & MAF from dbSNP & MAF & $\begin{array}{r}\text { P for HWE in very low } \\
\text { caries experience group }\end{array}$ \\
\hline rs2274328 & & & 0.29 \\
rs17032907 & $\mathrm{A} / \mathrm{C}$ & 0.4936 & 0.4 & 0.089 \\
rs11576766 & $\mathrm{C} / \mathrm{T}$ & 0.2163 & 0.3915 & 0.876 \\
rs2274333 & $\mathrm{A} / \mathrm{C}$ & 0.3678 & 0.4167 & 0.638 \\
rs10864376 & $\mathrm{G} / \mathrm{A}$ & 0.3246 & 0.3598 & 0.185 \\
rs3765964 & $\mathrm{T} / \mathrm{C}$ & 0.4917 & 0.3028 & 0.117 \\
rs6680186 & $\mathrm{T} / \mathrm{C}$ & 0.4504 & 0.2968 & \\
\hline
\end{tabular}

Table 4. Genotype frequencies and OR $(95 \% \mathrm{CI})$ for association between CA VI polymorphisms and caries risk.

\begin{tabular}{|c|c|c|c|c|c|c|c|}
\hline \multirow[t]{2}{*}{ dbSNP } & \multirow{2}{*}{$\begin{array}{l}\text { Major/minor } \\
\text { allele }\end{array}$} & \multirow{2}{*}{$\begin{array}{l}\text { Higher caries experience } \\
\qquad(\mathrm{DMFT} \geq 3) \mathrm{N}(\%)\end{array}$} & \multirow{2}{*}{$\begin{array}{l}\text { Very low caries experience } \\
\qquad(\mathrm{DMFT} \leq 2) \mathrm{N}(\%)\end{array}$} & \multicolumn{2}{|c|}{ Co-dominant model } & \multicolumn{2}{|c|}{ Dominant model } \\
\hline & & & & OR $(95 \% \mathrm{CI})$ & $\mathrm{P}$ & OR $(95 \% \mathrm{CI})$ & $\mathrm{P}$ \\
\hline \multirow[t]{3}{*}{ rs 2274328} & AA & $61(37.2 \%)$ & $68(35.6 \%)$ & & & & \\
\hline & $\mathrm{AC}$ & $70(42.7 \%)$ & $98(51.3 \%)$ & $0.797(0.502-1.268)$ & 0.335 & & \\
\hline & $\mathrm{CC}$ & $33(20.1 \%)$ & $25(13.1 \%)$ & $1.473(0.788-2.749)$ & 0.226 & $0.931(0.603-1.441)$ & 0.754 \\
\hline \multirow[t]{3}{*}{ rs17032907 } & $\mathrm{CC}$ & $59(36.0 \%)$ & $69(36.1 \%)$ & & & & \\
\hline & CT & $72(43.9 \%)$ & $104(54.5 \%)$ & $0.813(0.512-1.282)$ & 0.361 & & \\
\hline & TT & $33(20.1 \%)$ & $18(9.4 \%)$ & $2.144(1.096-4.195)$ & 0.025 & $0.990(0.642-1.528)$ & 0.961 \\
\hline \multirow[t]{3}{*}{ rs11576766 } & AA & $78(49.7 \%)$ & $81(44.8 \%)$ & & & & \\
\hline & $\mathrm{AC}$ & $57(36.3 \%)$ & $79(43.6 \%)$ & $0.743(0.473-1.186)$ & 0.22 & & \\
\hline & $\mathrm{CC}$ & $22(14.0 \%)$ & $21(11.6 \%)$ & $1.086(0.551-2.138)$ & 0.804 & $0.822(0.535-1.251)$ & 0.368 \\
\hline \multirow[t]{3}{*}{ rs 2274333} & GG & $62(37.8 \%)$ & $62(32.6 \%)$ & & & & \\
\hline & AG & $71(43.3 \%)$ & $94(49.5 \%)$ & $0.754(0.472-1.205)$ & 0.238 & & \\
\hline & $\mathrm{AA}$ & $31(18.9 \%)$ & $34(17.9 \%)$ & $0.911(0.503-1.668)$ & 0.766 & $0.793(0.511-1.233)$ & 0.309 \\
\hline \multirow[t]{3}{*}{ rs10864376 } & TT & $68(41.7 \%)$ & $75(39.5 \%)$ & & & & \\
\hline & CT & $74(45.4 \%)$ & $92(48.4 \%)$ & $0.884(0.563-1.396)$ & 0.601 & & \\
\hline & $\mathrm{CC}$ & $21(12.9 \%)$ & $23(12.1 \%)$ & $1.004(0.511-1.984)$ & 0.986 & $0.916(0.597-1.391)$ & 0.663 \\
\hline \multirow{3}{*}{ rs3765964 } & TT & $83(50.6 \%)$ & $85(44.5 \%)$ & & & & \\
\hline & CT & $68(41.5 \%)$ & $91(47.6 \%)$ & $0.763(0.494-1.186)$ & 0.224 & & \\
\hline & $\mathrm{CC}$ & $13(7.9 \%)$ & $15(7.9 \%)$ & $0.884(0.396-1.975)$ & 0.773 & $0.782(0.516-1.187)$ & 0.254 \\
\hline \multirow[t]{3}{*}{ rs6680186 } & $\mathrm{AA}$ & $82(50.9 \%)$ & $86(46.2 \%)$ & & & & \\
\hline & AG & $64(39.8 \%)$ & $88(47.3)$ & $0.764(0.496-1.189)$ & 0.224 & & \\
\hline & GG & $15(9.3 \%)$ & $12(6.5 \%)$ & $1.317(0.573-2.961)$ & 0.516 & $0.822(0.541-1.263)$ & 0.386 \\
\hline
\end{tabular}

Adjusted for gender and age; Total number of each SNP is different because genotypes of some SNPs are unreadable. 


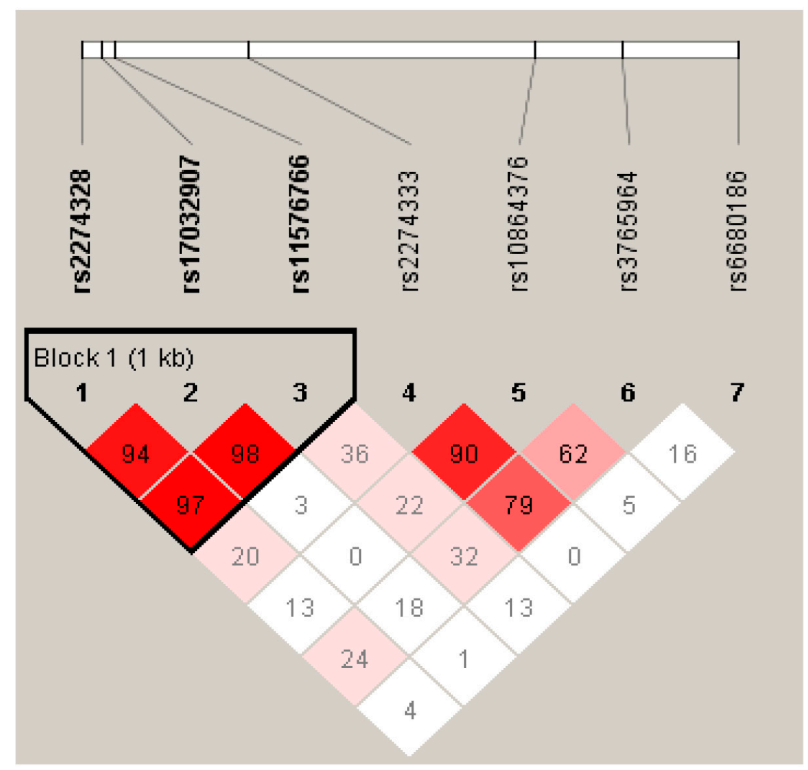

Figure 1. Linkage disequilibrium block of CA VI gene. The block 1 of polymorphisms were tested using Haploview 4.2 and estimated with D'. D' (rs2274328-rs17032907) = 0.94; D' (rs2274328-rs11576766) =0.97; D' (rs17032907rs11576766) $=0.98$.

Table 5. Haplotype analysis in block 1 of CA VI gene.

\begin{tabular}{|c|c|c|c|c|c|c|c|c|c|c|}
\hline \multicolumn{3}{|c|}{ Haplotype } & \multirow[t]{2}{*}{ Frequency } & \multicolumn{2}{|c|}{ Case group } & \multicolumn{2}{|c|}{ Control group } & \multirow[t]{2}{*}{ Chi Square } & \multirow[t]{2}{*}{$P$ value } & \multirow[t]{2}{*}{ Odds ratio $(95 \% \mathrm{CI})$} \\
\hline rs2274328 & rs17032907 & rs 11576766 & & + & - & + & - & & & \\
\hline A & $\mathrm{T}$ & A & 0.382 & 134.1 & 193.9 & 137 & 245 & 1.865 & 0.172 & $1.235(0.912-1.673)$ \\
\hline $\mathrm{C}$ & $\mathrm{C}$ & $\mathrm{C}$ & 0.329 & 106.3 & 221.7 & 127 & 255 & 0.054 & 0.8165 & $0.959(0.700-1.313)$ \\
\hline A & $\mathrm{C}$ & A & 0.213 & 56.8 & 271.2 & 94.6 & 287 & 5.861 & 0.0155 & $0.635(0.440-0.918)$ \\
\hline $\mathrm{C}$ & $\mathrm{C}$ & A & 0.062 & 25.8 & 302.2 & 18.1 & 364 & 2.945 & 0.0862 & $1.741(0.937-3.236)$ \\
\hline
\end{tabular}

Each haplotype with a frequency more than 0.1 is shown; P values of haplotype association were calculated by Haploview 4.2; “+”means appearance, “-”means not appearance.

\section{DISCUSSION}

In the present study, we examined the contribution of 7 polymorphisms in the CA VI gene to the susceptibility to dental caries in Chinese populations. In order to reduce sample heterogeneity, we compared individuals living in the same area and with similar food cultures, oral health habits, water fluorine concentration, and access to oral care.

To identify useful makers for predicting susceptibility to dental caries, we selected 7 polymorphisms (rs2274328, rs17032907, rs11576766, rs2274333, rs10864376, rs3765964, and rs6680186 in exon $2 / 3$ or in the intron region) of the CA VI gene with potential consequences. We found that the genotype of the rs $17032907(\mathrm{C} / \mathrm{T})$ variant increased DMFT scores, while the haplotype (ACA) (rs2274328, rs17032907, and rs11576766) was associated with a lower DMFT index. This is the first study to construct related haplotypes and investigate the 
genetic impact of the CA VI intron region on dental caries.

Only 4 studies have investigated the association between CA VI gene polymorphisms and dental caries susceptibility, but found no direct relationship with dental caries. In 2009, Yarat et al. (2009) reported that these studies found no differences in the frequency of the SNPs [rs2274327 (C/T), rs2274328 (A/C)], salivary $\mathrm{pH}$, and buffering capacity among Turkish dental students with caries and those who were caries-free. However, a later study including 245 children investigated the same 2 SNPs and reported that 1 SNP [rs2274327 (C/T)] was associated with a decrease in salivary buffering capacity in healthy children, but that the gene polymorphisms were not directly related to caries (Peres et al., 2010). Recently, 4 SNPs [rs2274327(C/T), rs2274328 (A/C), rs2274329 (G/C), and rs2274330 (G/C)] were studied in 43 subjects, and no correlation was found between SNPs in CA VI exon 2 and salivary buffering capacity or $\mathrm{pH}$; however, a positive significant correlation was found between salivary $\mathrm{CA}$ activity and the frequency of SNPs in exon 2 of CA VI in diabetic groups (Koç et al., 2012). A recent study showed that individuals with the TT genotype (rs2274327) had significantly lower CA VI concentrations than individuals with genotypes CT or CC $(\mathrm{P}<0.05)$. There was also an association between the polymorphism rs2274333 and salivary CA VI concentrations, suggesting that polymorphisms in CA6 gene are associated with the concentrations of secreted CA VI (Aidar et al., 2013). The results of this study support an association between CA VI gene polymorphisms and dental caries susceptibility in Chinese subjects. Some SNPs may alter enzyme structure, affecting CA VI function.

In summary, we found that CA VI harbors potentially important polymorphic variants. The rs17032907 genetic variant and the haplotype (ACA) of the CA VI gene may be associated with susceptibility to caries and can be used to predict the risk of dental caries in our samples. However, further studies including larger numbers of samples of different ethnic groups are required for further evaluation and confirmation of our findings.

\section{ACKNOWLEDGMENTS}

Research supported by a grant from the International Technology Cooperation Projects in Gansu province (\#2009GS03605).

\section{REFERENCES}

Aidar M, Marques R, Valjakka J, Mononen N, et al. (2013). Effect of genetic polymorphisms in CA6 gene on the expression and catalytic activity of human salivary carbonic anhydrase VI. Caries Res. 47: 414-420.

Azevedo LF, Pecharki GD, Brancher JA, Cordeiro CA Jr, et al. (2010). Analysis of the association between lactotransferrin (LTF) gene polymorphism and dental caries. J. Appl. Oral Sci. 18: 166-170.

Bretz WA, Corby PM, Schork NJ, Robinson MT, et al. (2005). Longitudinal analysis of heritability for dental caries traits. J. Dent. Res. 84: 1047-1051.

Davenport H (1939). Gastric carbonic anhydrase. J. Physiol. 97: 32 -43

Deeley K, Letra A, Rose EK, Brandon CA, et al. (2008). Possible association of amelogenin to high caries experience in a Guatemalan-Mayan population. Caries Res. 42: 8-13.

Henkin RI, Martin BM and Agarwal RP (1999). Decreased parotid saliva gustin/carbonic anhydrase VI secretion: an enzyme disorder manifested by gustatory and olfactory dysfunction. Am. J. Med. Sci. 318: 380-391.

Hunt HR, Hoppert CA and Erwin WG (1944). Inheritance of susceptibility to caries in albino rats. J. Dent. Res. 23: 385-401.

Jiang W and Gupta D (1999). Structure of the carbonic anhydrase VI (CA6) gene: evidence for two distinct groups within the alpha-CA gene family. Biochem. J. 344: 385-390.

Kadoya Y, Kuwahara H, Shimazaki M, Ogawa Y, et al. (1987). Isolation of a novel carbonic anhydrase from human saliva and immunohistochemical demonstration of its related isoenzymes in salivary gland. Osaka City Med. J. 33: 99-109. 
Klein H (1946). The family and dental disease; dental disease (DMF) experience in parents and offspring. J. Am. Dent. Assoc. 33: 735-743.

Kang SW, Yoon I, Lee, HW and Cho J (2011). Association between AMELX polymorphisms and dental caries in Koreans. Oral Dis. 17: 399-406.

Kimoto M, Kishino M, Yura Y and Ogawa Y (2006). A role of salivary carbonic anhydrase VI in dental plaque. Arch. Oral Biol. 51: 117-122.

Kivelä J, Parkkila S, Metteri J, Parkkila AK, et al. (1997). Salivary carbonic anhydrase VI concentration and its relation to basic characteristics of saliva in young men. Acta Physiol. Scand. 161: 221-225.

Kivelä J, Parkkila S, Parkkila AK, Leinonen J et al. (1999a). Salivary carbonic anhydrase isoenzyme VI. J. Physiol. 520 : 315-320.

Kivelä J, Parkkila S, Parkkila AK and Rajaniemi H (1999b). A low concentration of carbonic anhydrase isoenzyme VI in whole saliva is associated with caries prevalence. Caries Res. 33: 178-184.

Koç Öztürk L, Ulucan K, Akyüz S, Furuncuoğlu H, et al. (2012). The investigation of genetic polymorphisms in the carbonic anhydrase VI gene exon 2 and salivary parameters in type 2 diabetic patients and healthy adults. Mol. Biol. Rep. 39: 5677-5682.

Leinonen J, Kivelä J, Parkkila S, Parkkila AK, et al. (1999). Salivary carbonic anhydrase isoenzyme VI is located in the human enamel pellicle. Caries Res 33: 185-190.

Lenander-Lumikari M and Loimaranta V (2000). Saliva and dental caries. Adv. Dent. Res. 14: 40-47.

Lewontin RC (1964). The interaction of selection and linkage. I. General considerations; heterotic models. Genetics 49: 49-67.

Mattila KJ, Valtonen VV, Nieminen M, Huttunen JK et al. (1995). Dental infection and the risk of new coronary events: Prospective study of patients with documented coronary artery disease. Clin. Infect. Dis. 20: 588-592.

Nariyama M, Shimizu K, Uematsu T and Maeda T (2004). Identification of chromosomes associated with dental caries susceptibility using quantitative trait locus analysis in mice. Caries Res. 38: 79-84.

Ozturk A, Famili P and Vieira AR (2010). The antimicrobial peptide DEFB1 is associated with caries. J. Dent. Res. 89: 631-636.

Padiglia A, Zonza A, Atzori E, Chillotti C, et al. (2010). Sensitivity to 6-n-propylthiouracil is associated with gustin (carbonic anhydrase VI) gene polymorphism, salivary zinc, and body mass index in humans. Am. J. Clin. Nutr. 92: 539-545.

Patir A, Seymen F, Yildirim M, Deeley K, et al. (2008). Enamel formation genes are associated with high caries experience in Turkish children. Caries Res. 42: 394-400.

Peres RC, Camargo G, Mofatto LS, Cortellazzi KL, et al. (2010). Association of polymorphisms in the carbonic anhydrase 6 gene with salivary buffer capacity, dental plaque ph, and caries index in children aged 7-9 years. Pharmacogenomics J. 10: 114-119.

Petersen PE (2003). The World Oral Health Report 2003: continuous improvement of oral health in the 21st century-the approach of the WHO Global Oral Health Programme. Community Dent. Oral Epidemiol. 31 (Suppl 1): 3-24.

Shelling AN and Ferguson LR (2007). Genetic variation in human disease and a new role for copy number variants. Mutat. Res. 622: 33-41.

Shuler CF (2001). Inherited risks for susceptibility to dental caries. J. Dent. Educ. 65: 1038-1045.

Szabó I (1974). Carbonic anhydrase activity in the saliva of children and its relation to caries activity. Caries Res. 8: 187-191.

World Health Organization (1997). Oral health surveys: basic methods, 4th edn. World Health Organization: Geneva, pp. 1-21.

Yarat A, Koc-Ozturk L, Ulucan K, Akyuz K, et al. (2009). Determination of association between CA VI genetic polymorphism and dental caries among Turkish dental students. IUBMB Life 61: 329. 